\title{
Copper impurities in bulk ZnO: A hybrid density functional study
}

\author{
Federico Gallino and Cristiana Di Valentin ${ }^{\text {a) }}$ \\ Dipartimento di Scienza dei Materiali, Università di Milano-Bicocca, Via R. Cozzi 53, 20125 Milano, Italy
}

(Received 11 January 2011; accepted 16 March 2011; published online 13 April 2011)

\begin{abstract}
Transition metal doping of $\mathrm{ZnO}$ is considered as a promising way to obtain a diluted magnetic semiconducting oxide. In this work we investigate copper doping of $\mathrm{ZnO}$ by means of density functional theory, using a hybrid exchange-correlation functional and a periodic approach with localized atomic basis functions. Isolated copper species, such as copper substitutional to zinc, $\mathrm{Cu}_{\mathrm{s}}$, and $\mathrm{Cu}$ interstitial, $\mathrm{Cu}_{\mathrm{i}}$, are analyzed in terms of transition energy levels and hyperfine coupling constants with reference to available spectroscopic data. We also examine the potential magnetic interaction between copper species, their interaction with oxygen vacancies, and the possibility of copper clustering. The relative stability of the various copper impurities considered in this study is finally compared on the basis of their formation energy at different oxygen chemical potentials and Fermi level values. (C) 2011 American Institute of Physics. [doi:10.1063/1.3575198]
\end{abstract}

\section{INTRODUCTION}

Zinc oxide is a wide band gap semiconductor with promising applications in optoelectronics and spintronics. ${ }^{1,2}$ For example, $\mathrm{ZnO}$ based optoelectronic devices, such as light emitting and laser diodes or transparent electrodes for flat panel displays and solar cells, are considered a viable alternative to the corresponding more expensive GaN and ITO (indium tin oxide) based ones. Additionally, the introduction of spin carriers by means of a dilute controlled doping is expected to open the way to new magnetic, electronic, and optical functionalities of the material. In this sense transition metal (TM) doped $\mathrm{ZnO}$ stands as a promising candidate for diluted magnetic semiconducting oxide to be used in electrically controlled magnetic sensors, spin-light-emitting diodes and spin-field effect transistors. ${ }^{3,4}$ Achievement of room temperature (RT) ferromagnetism by $\mathrm{Mn}$ and $\mathrm{Cu}$ doping, avoiding unwanted secondary ferromagnetic phases due to metal clustering, is the final goal of nowadays experimental effort. ${ }^{3} \mathrm{~A}$ few theoretical studies ${ }^{5,6}$ have already inspired some experimental work, although initial expectations were not fulfilled by actual results. ${ }^{7-9}$ In a recent work, Zunger et al. ${ }^{10}$ questioned the reliability of the reported theoretical predictions pointing at the severe limitations of pure density functional theory approximations [local density approximation (LDA) and generalized gradient approximation (GGA)] in correctly and accurately describing band gap values and spin localization, both essential components when investigating TM doped semiconductors. The critical problem of state of the art methods in describing such complex systems as $\mathrm{Cu}$-doped $\mathrm{ZnO}$ can largely benefit from a detailed comparison of a number of computed properties with available experimental data (in particular, defect or impurity levels position in the band gap from optical or photoluminescence spectroscopies ${ }^{11,12}$ and their electron paramagnetic resonance parameters ${ }^{13,14}$ ).

In this paper we present a detailed study of copper bulk impurities in $\mathrm{ZnO}$ using the popular hybrid B3LYP

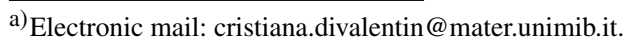

functional ${ }^{15,16}$ in combination with a localized atomic orbital basis-set approach for periodic calculations, as implemented in the CRYSTAL06 code. ${ }^{17}$ This method provides an improved description of fully or partially filled TM dstates and of all those properties which are not accurately described by LDA or GGA methods, as just mentioned above [e.g., band gap: B3LYP $3.38 \mathrm{eV}$ versus experimental 3.44 (Ref. 18)]. Computational results are compared to available experimental data whenever possible. On these bases, the present work has the major goal to provide a comprehensive overview investigation of copper doping in $\mathrm{ZnO}$ and to address several specific issues which are still under debate in the literature. Copper impurities are first investigated as wellestablished electron acceptors ${ }^{19}$ but secondly also as potential electron donors, in line with recent experimental findings. ${ }^{20}$ Acceptor and donor properties are discussed in terms of thermodynamic and optical transition levels from a recently proposed model. ${ }^{21}$ Then the controversial relative stability of ferromagnetic (FM) and antiferromagnetic (AFM) phases $^{22-27}$ for substitutional $\mathrm{Cu}$ to lattice $\mathrm{Zn}$ atoms is analyzed. Finally, the possibility of interaction with oxygen vacancies $^{24,25}$ and of copper clustering ${ }^{23,25,26}$ in bulk $\mathrm{ZnO}$ matrix is explored. The stability of all these diverse species has been compared on the basis of their formation energy, as a function of the Fermi level and of the oxygen chemical potential, which determines whether the system is in an oxidizing or reducing environment.

The paper is organized as follows. Section II provides details on the computational approach. In Sec. III, we report and discuss the results for the various defect centers considered. Section IV summarizes our conclusions and presents an overview on $\mathrm{Cu}$-doped $\mathrm{ZnO}$ system.

\section{COMPUTATIONAL DETAILS}

Spin-polarized periodic calculations were performed using the hybrid B3LYP exchange-correlation functional ${ }^{15,16}$ 
and the Kohn-Sham orbitals were expanded in Gaussian type orbitals, as implemented in CRYSTAL06 code. ${ }^{17}$ The all-electron basis set adopted is a $8-411(\mathrm{~d} 1)^{28}$ for oxygen, $8-64111(\mathrm{~d} 41)^{29}$ for zinc and $8-6411(\mathrm{~d} 41)^{30}$ for copper. In some cases results have been refined by performing single point calculations with larger basis sets: $8-64111(\mathrm{~d} 411)^{31}$ for zinc and 8-64111(d41) 32 for copper.

We considered a 192-atom supercell obtained by the expansion matrix $4 \times 4 \times 3$, for simulating the bulk $\mathrm{ZnO}$ (wurtzite, space group $\mathrm{P}_{3} \mathrm{mc}$ ). The bulk lattice parameters have been optimized for pure $\mathrm{ZnO}: \mathrm{a}=3.278 \AA, \mathrm{c}=5.287 \AA$. The copper impurity has been inserted: (i) substitutional (s) to $\mathrm{Zn}$ atoms: $\mathrm{Zn}_{1-\mathrm{x}} \mathrm{Cu}_{\mathrm{x}} \mathrm{O}\left(\mathrm{Cu}_{\mathrm{s}}, \mathrm{Cu}_{\mathrm{s}} \mathrm{Cu}_{\mathrm{s}}\right)$ and $\mathrm{Zn}_{1-\mathrm{x}} \mathrm{Cu}_{\mathrm{x}} \mathrm{Zn}_{\mathrm{y}} \mathrm{O}$ $\left(\mathrm{Cu}_{\mathrm{s}} \mathrm{Zn}_{\mathrm{i}}\right)$; (ii) interstitial (i): $\mathrm{ZnCu}_{\mathrm{y}} \mathrm{O}\left(\mathrm{Cu}_{\mathrm{i}}\right)$; (iii) in the presence of oxygen vacancies $\left(\mathrm{V}_{\mathrm{O}}\right): \mathrm{Zn}_{1-\mathrm{x}} \mathrm{Cu}_{\mathrm{x}} \mathrm{O}_{1-\mathrm{x}}\left(\mathrm{Cu}_{\mathrm{s}} \mathrm{V}_{\mathrm{O}}\right)$; and (iv) both interstitial and substitutional to $\mathrm{Zn}$ atoms: $\mathrm{Zn}_{1-\mathrm{x}} \mathrm{Cu}_{\mathrm{x}+\mathrm{y}} \mathrm{O}\left(\mathrm{Cu}_{\mathrm{s}} \mathrm{Cu}_{\mathrm{i}}, \mathrm{Cu}_{\mathrm{s}} 2 \mathrm{Cu}_{\mathrm{i}}\right)$. The copper atomic concentration has been varied in the range $\mathrm{x}+\mathrm{y}=0.0104 \div 0.0312$ for the various defects considered $\left[\mathrm{x}=0.0104\left(\mathrm{Cu}_{\mathrm{s}}, \mathrm{Cu}_{\mathrm{s}} \mathrm{V}_{\mathrm{O}}\right.\right.$, $\left.\mathrm{Cu}_{\mathrm{s}} \mathrm{Cu}_{\mathrm{i}}, \mathrm{Cu}_{\mathrm{s}} 2 \mathrm{Cu}_{\mathrm{i}}\right), \mathrm{x}=0.0208\left(\mathrm{Cu}_{\mathrm{s}} \mathrm{Cu}_{\mathrm{s}}\right), \mathrm{y}=0.0104\left(\mathrm{Cu}_{\mathrm{i}}\right.$, $\left.\left.\mathrm{Cu}_{\mathrm{s}} \mathrm{Zn}_{\mathrm{i}}, \mathrm{Cu}_{\mathrm{s}} \mathrm{Cu}_{\mathrm{i}}\right), \mathrm{y}=0.0208\left(\mathrm{Cu}_{\mathrm{s}} 2 \mathrm{Cu}_{\mathrm{i}}\right)\right]$.

The reciprocal space was sampled by a $2 \times 2 \times 2$ k-point mesh corresponding to $4 \div 8 \mathrm{k}$-points of the irreducible Brillouin zone. ${ }^{17}$ The atomic positions were fully relaxed until the largest component of the ionic forces was less than $4.5 \times 10^{-4}$ a.u.. The densities of states were computed with a $3 \times 3 \times 3$ k-point mesh. The Kohn-Sham eigenvalues were computed on each $\mathrm{k}$ point but only those at $\Gamma$ are discussed in the manuscript because of the direct band gap of
$\mathrm{ZnO}$. The zero point of orbital energy was set to the top of the valence band (VB).

The hyperfine interactions of the unpaired electron spin with the nuclear spin of the ${ }^{63} \mathrm{Cu}$ nuclide have been determined. The hyperfine spin-Hamiltonian, $H_{\mathrm{hfc}}=\mathbf{S} \cdot \mathbf{A} \cdot \mathbf{I}$, is given in terms of the hyperfine matrix $A$, which describes the coupling of the electron with the nuclear spin. ${ }^{33}$ The components of $A$ can be represented as

$$
A=\left[\begin{array}{ccc}
A_{1} & 0 & 0 \\
0 & A_{2} & 0 \\
0 & 0 & A_{3}
\end{array}\right]=a_{\mathrm{iso}} U+\left[\begin{array}{ccc}
B_{1} & 0 & 0 \\
0 & B_{2} & 0 \\
0 & 0 & B_{3}
\end{array}\right]
$$

where $\mathrm{U}$ is the unit matrix. The isotropic part, $a_{\mathrm{iso}}$, of each coupling constant is related to the spin density at the nucleus (the Fermi contact term).

The approach employed to estimate the position of the thermodynamic and optical transition energy levels $\left(\varepsilon^{\text {therm }}\right.$ and $\varepsilon^{\mathrm{opt}}$ ) in the band gap of the material for all the investigated $\mathrm{Cu}$ defects has been described in a previous paper. ${ }^{21}$ We refer to this work and to the supplementary material ${ }^{34}$ for all the details of the methodology $y^{35}$ and for the meaning of the transition energy levels with reference to experimental spectroscopic data, such as thermal ionization energies or photoluminescence emissions whose comparison will be discussed here for the specific case of $\mathrm{Cu}$-doped $\mathrm{ZnO}$. Thermodynamic transition levels are derived from optical transition levels by addition of the relaxation energy, $E_{\text {rel }}$, computed as the
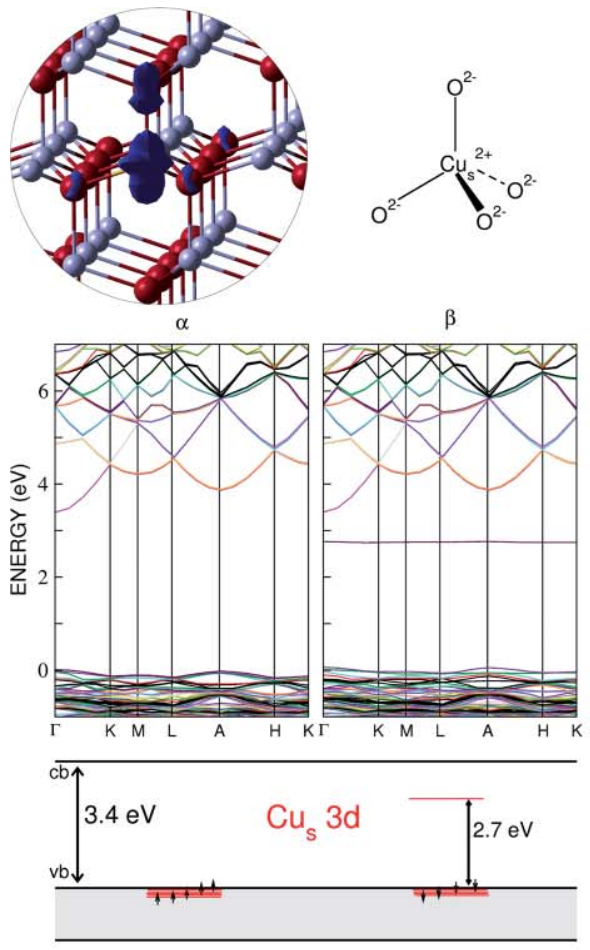

a) $\mathrm{Cu}_{\mathrm{s}}$

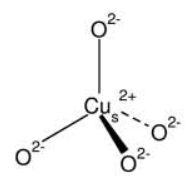

$\beta$

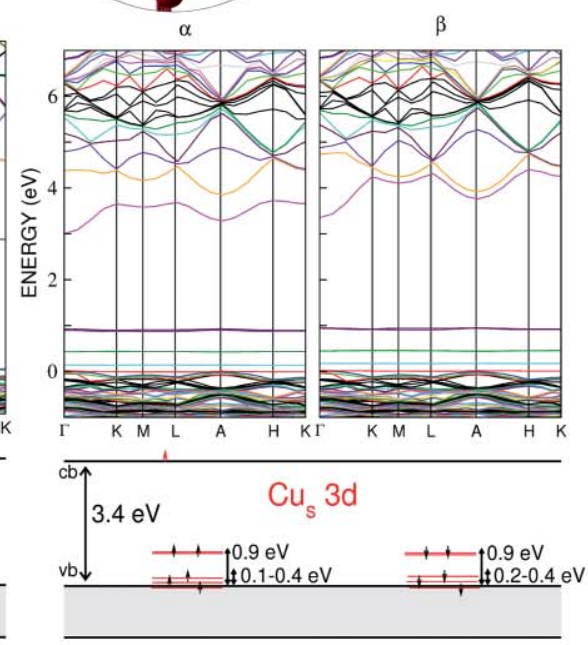

b) $\mathrm{Cu}_{\mathrm{s}} \mathrm{Zn}_{\mathrm{i}}$

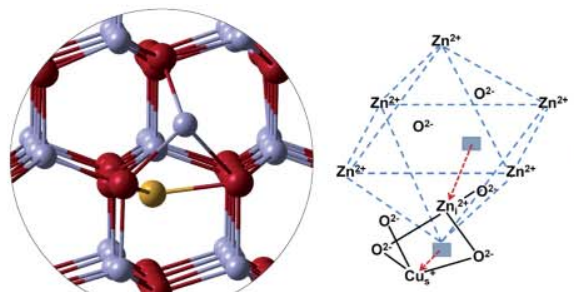

$\beta$

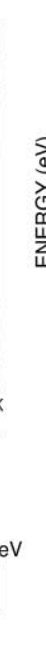

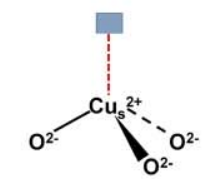

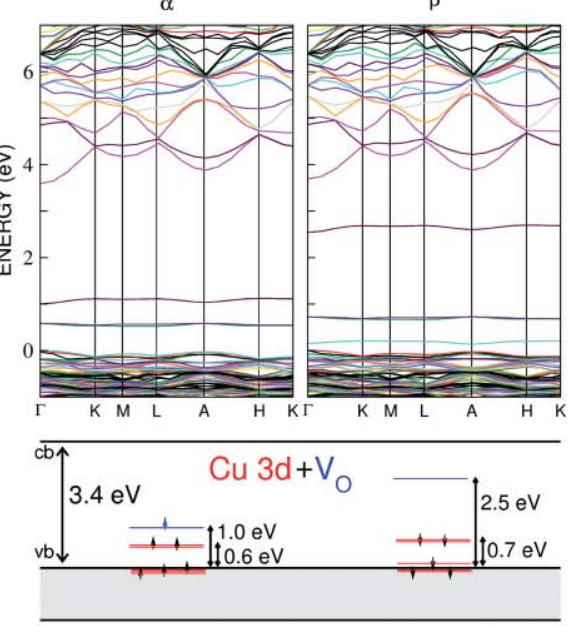

c) $\mathrm{Cu}_{\mathrm{s}} \mathrm{V}_{\mathrm{O}}$

FIG. 1. Upper panel: spin density plot and schematic structure of the (a) $\mathrm{Cu}_{\mathrm{s}}$ and (c) $\mathrm{Cu}_{\mathrm{s}} \mathrm{V}_{\mathrm{O}}$ species in bulk $\mathrm{ZnO}$. Ball and stick and schematic representations of the (b) $\mathrm{Cu}_{\mathrm{s}} \mathrm{Zn}_{\mathrm{i}}$ species in bulk $\mathrm{ZnO}$. $\mathrm{Zn}, \mathrm{O}$, and $\mathrm{Cu}$ are represented by gray, red, and yellow spheres, respectively. Lower panel: band structures together with a schematic representation of the electronic structure (from Kohn-Sham eigenvalues in $\Gamma$ ). Red and blue arrows represent the unpaired electron delocalized in the $\mathrm{CB}$ for (b) and the unpaired electron localized in the $\mathrm{V}_{\mathrm{O}}$ for $(\mathrm{c})$, respectively. 

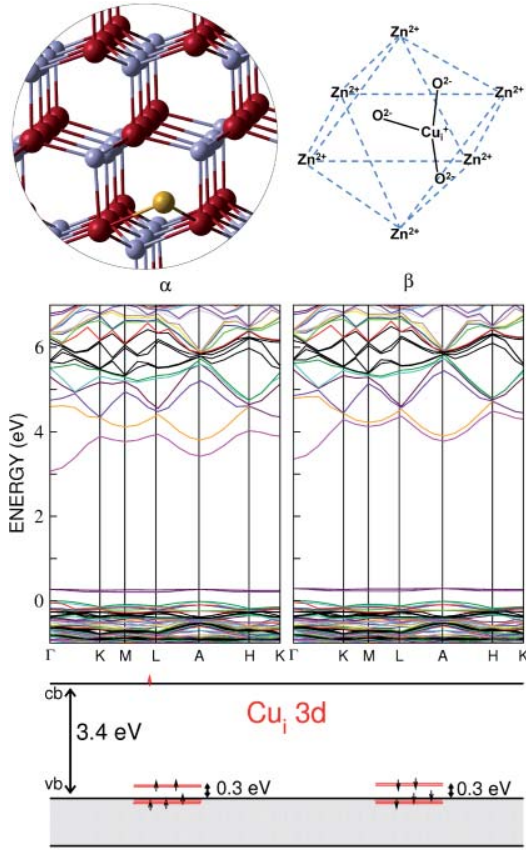

a) $\mathrm{Cu}_{\mathrm{i}}$

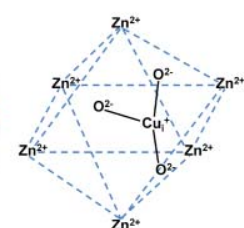

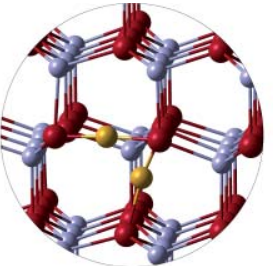
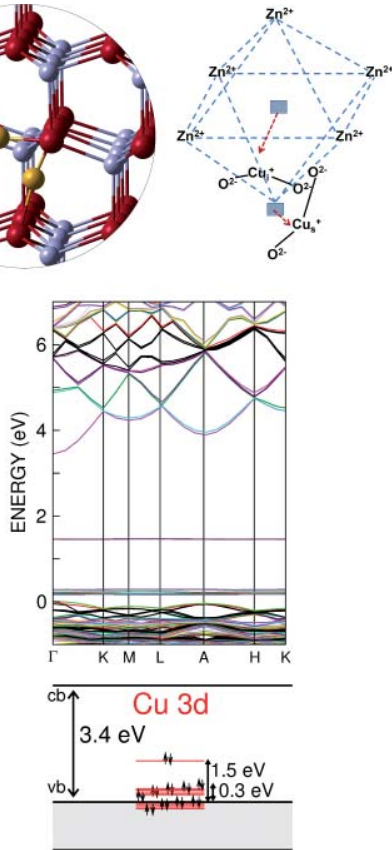

b) $\mathrm{Cu}_{5} \mathrm{Cu}_{\mathrm{i}}$
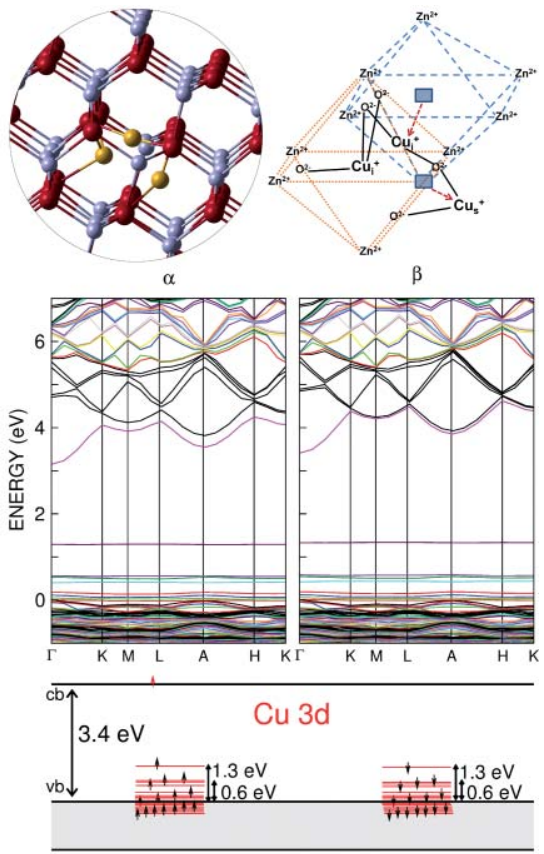

c) $\mathrm{Cu}_{\mathrm{s}} 2 \mathrm{Cu}$

FIG. 2. Upper panel: ball and stick and schematic structures of the (a) $\mathrm{Cu}_{\mathrm{i}}$, (b) $\mathrm{Cu}_{\mathrm{s}} \mathrm{Cu}_{\mathrm{i}}$ and (c) $\mathrm{Cu}_{\mathrm{s}} 2 \mathrm{Cu}_{\mathrm{i}}$ species in bulk $\mathrm{ZnO}$. $\mathrm{Zn}$, $\mathrm{O}$, and $\mathrm{Cu}$ are represented by gray, red, and yellow spheres, respectively. Lower panel: band structures together with a schematic representation of the electronic structure (from Kohn-Sham eigenvalues in $\Gamma$ ). The red arrow represents the unpaired electron delocalized in the CB for (a) and (c).

total energy difference between the charged state in its relaxed configuration and in the neutral relaxed configuration.

\section{RESULTS AND DISCUSSION}

Various models of copper impurities in $\mathrm{ZnO}$ have been investigated in this work, as detailed in Sec. II. In the following we first present monoelemental species: copper substitutional to zinc $\left[\mathrm{Cu}_{\mathrm{s}}\right.$ in Fig. 1(a)] and copper interstitial $\left[\mathrm{Cu}_{\mathrm{i}}\right.$ in Fig. 2(a)]. The possibility that the copper atom kicks out a zinc atom from its lattice position, resulting in $\mathrm{Cu}_{\mathrm{s}}$ in the presence of an interstitial zinc atom $\left[\mathrm{Cu}_{\mathrm{s}} \mathrm{Zn}_{\mathrm{i}}\right.$ in Fig. 1(b)] is also explored. Second, higher local concentrations of copper atoms are considered to account for possible multiatom doping or clustering effects. Finally, the interplay between copper impurities and possible intrinsic defects of bulk zinc oxide, such as oxygen vacancies, is discussed.

\section{A. Substitutional copper (to zinc): $\mathrm{Cu}_{\mathrm{s}}$ and $\mathrm{Cu}_{\mathrm{s}} \mathrm{Zn}_{\mathrm{i}}$}

\section{1. $C u_{s}$}

Copper substitutional to zinc $\left(\mathrm{Cu}_{\mathrm{s}}\right)$ in $\mathrm{ZnO}$ has been largely studied in literature. From an experimental point of view, copper doping of zinc oxide single crystal was easily achieved by pulsed laser techniques, ${ }^{8,9}$ ion implantation, ${ }^{12,36}$ flux methods ${ }^{13,37}$ and high temperature treatments. ${ }^{38,39}$ In particular, in a recent work based on the emission channeling technique, ${ }^{36}$ it has been demonstrated that $\sim 70 \%$ of $\mathrm{Cu}$ atoms are substitutional to zinc with root mean square displacements of $0.16-0.17 \AA$ from the original lattice site. Copper is in a $2+$ formal oxidation state, $\mathrm{Cu}_{\mathrm{s}}{ }^{2+}$, replacing a $\mathrm{Zn}^{2+}$ lattice ion and the overall system is thus charge neutral. $\mathrm{Cu}_{\mathrm{s}}{ }^{2+}$ is reported to be an acceptor species, responsible of the typical green luminescence in $\mathrm{ZnO}$ with a zero-phonon doublet at $2.86 \mathrm{eV}$, analyzed by the pioneering work of Dingle. ${ }^{11}$ This emission was attributed to the transition from an excited $\mathrm{Cu}_{\mathrm{s}}{ }^{+}$ $3 d^{10} 4 s^{0}$ state $\left[\mathrm{A}^{-}\right]$to the $\mathrm{Cu}_{\mathrm{s}}{ }^{2+} 3 d^{9} 4 s^{0}$ state $\left[\mathrm{A}^{0}\right]$ and its corresponding acceptor transition level $(0 /-1)$, in the semiconductor terminology, was estimated at 0.17 (Ref. 37) and 0.19 $\mathrm{eV}$ (Ref. 40) below the conduction band (CB) by electrical measurements. ${ }^{19}$ The discrepancy in the position of the state as obtained by luminescence and electrical measurements is a consequence of a large Stoke shift in the former case.

The presence of a hole in the $\mathrm{Cu}_{\mathrm{s}}{ }^{2+} 3 d$ shell [see Fig. 1(a)] causes a Jahn-Teller distortion of the tetrahedral coordination with a shortened axial $\mathrm{Cu}-\mathrm{O}$ distance from 2.00 to $1.91 \AA$. The unpaired electron is highly localized on a $\mathrm{Cu}$ $d$-orbital pointing toward the closest oxygen. All the $\mathrm{Cu} 3 d$ states are localized inside the VB, except for the unoccupied beta spin component, $2.7 \mathrm{eV}$ above the VB top [Fig. 1(a)]. The addition of one extra electron fills up the $\mathrm{Cu} 3 d$ shell and induces a considerable outward relaxation of the nearest $\mathrm{O}$ atoms by $4 \% \div 9 \%$, restoring the original tetrahedral coordination. The corresponding relaxation energy, $E_{\text {rel }}$, is $0.58 \mathrm{eV}$ and the $\mathrm{Cu} 3 d$ states are lifted up in the band gap and splitted by the crystal field in e and $t_{2}$ components.

a. Transition levels. The transition levels $(0 /-1)$ computed in the present work with the hybrid functional B3LYP are consistent with the experimental data (see Table I), and a recent work by Lany and Zunger ${ }^{41}$ using a GGA $+\mathrm{U}$ method and applying a hole-state correction for the $\mathrm{Zn}$ and $\mathrm{Cu} d$ 
TABLE I. Optical and thermodynamic transition levels for some selected $\mathrm{Cu}$ defects considered in this work (in $\mathrm{eV}$ ).

\begin{tabular}{lcccc}
\hline \hline Defect & Transition & $\varepsilon(q / q)^{\text {therm }}$ & $\varepsilon\left(q / q^{\prime}\right)^{\text {opt }}$ & $E_{\text {rel }}$ \\
\hline $\mathrm{Cu}_{\mathrm{s}}$ & $(0 /-1)$ & 2.48 & 3.06 & 0.58 \\
$\mathrm{Cu}_{\mathrm{i}}$ & $(+1 / 0)$ & 3.26 & 3.20 & 0.06 \\
$\mathrm{Cu}_{\mathrm{s}} \mathrm{Zn}_{\mathrm{i}}$ & $(+1 / 0)$ & 3.27 & 3.13 & 0.14 \\
$\mathrm{Cu}_{\mathrm{s}} 2 \mathrm{Cu}_{\mathrm{i}}$ & $(+1 / 0)$ & 3.30 & 3.27 & 0.03 \\
$\mathrm{Cu}_{\mathrm{s}} \mathrm{V}_{\mathrm{O}}$ & $(+1 / 0)$ & 2.27 & 1.12 & 1.15 \\
\hline \hline
\end{tabular}

states. The green luminescence centered at $2.86 \mathrm{eV}$ corresponds to the $\mathrm{PL}_{2}$ transition (see Ref. 21 or Figs. S1 and S2 in Ref. 34 for details) where the excited electron decays from the defect $\mathrm{A}^{-}\left(\mathrm{Cu}_{\mathrm{s}}{ }^{+}\right)$to the valence band according to the Franck-Condon principle. Depending on the residence time of the electron at the $\mathrm{Cu}_{\mathrm{s}}{ }^{+}$defect, the emission peak should range from $\left[\varepsilon^{\text {therm }}(0 /-1)-E^{\prime}\right.$ rel $]$ to $\varepsilon^{\text {opt }}(0 /-1),{ }^{42}$ computed from 1.96 to $3.06 \mathrm{eV}$, respectively, in good agreement with the experimental peak at $2.86 \mathrm{eV}$. Previous theoretical works based on LDA and GGA calculations reported transition levels closer to the VB [0.7 (Ref. 43) and $0.98 \mathrm{eV}$ (Ref. 23), respectively] that were erroneously interpreted as the origin of the green luminescence according to a $\mathrm{PL}_{1}$ type transition with the excited electron recombining at the defect level (see Ref. 21 or Figs. S1 and S2 in Ref. 34 for details). These calculations are severely affected by the band-gap error and the self-interaction problem, two well-known shortcomings of standard DFT methods.

b. Electron paramagnetic resonance properties. Being substitutional copper to zinc a paramagnetic species in $\mathrm{ZnO}\left(\mathrm{Cu}_{\mathrm{s}}{ }^{2+} 3 d^{9} 4 s^{0}\right)$, it has been investigated by several groups with the electron paramagnetic resonance (EPR) spectroscopy. The continuous wave EPR spectrum of $\mathrm{Cu}_{\mathrm{s}}{ }^{2+}$ in a single crystal $\mathrm{ZnO}$ was first reported by Dietz et al. ${ }^{13}$ and consists of an $S=1 / 2$ species with axial symmetry, interacting with a single $\mathrm{Cu}$ nucleus resulting in a well-resolved hyperfine pattern due to the two copper isotopes $\left({ }^{63} \mathrm{Cu}, I\right.$ $=3 / 2,69.2 \%$ abundant and ${ }^{65} \mathrm{Cu}, I=3 / 2,30.8 \%$ abundant). The interpretation of the large $g$ shifts and hyperfine coupling constants, (see Table II), much debated in literature, ${ }^{13,14,44-48}$ is still an open question. In particular two main currents of thought can be identified. From one side Dietz et al. ${ }^{13}$ proposed a model of interpretation of $g$-shifts involving a considerable covalency with the $3 d$ hole spending $40 \%$ of its time on neighboring oxygens. The major criticism to this theory is related to the anomalously large overlap integral between the $3 d$ and oxygen orbitals, ${ }^{44}$ in contrast with the experimentally estimated $90 \%$ ionic character of $\mathrm{ZnO} .{ }^{49}$ From the other side, Bates ${ }^{45}$ drew the attention to the possible hybridization of the $3 d^{9}$ ground state with the $3 d^{8} 4 p^{1}$ excited state. According to this hypothesis, the hole is estimated to spend $67.5 \%$ and $7.5 \%$ of its time in the $3 d$ and $4 p$ orbitals, respectively, which would also explain the large hyperfine coupling constants.

Here, we present for the first time the $a b$ initio computation of hyperfine coupling constants for the model of substitutional copper in $\mathrm{ZnO}$ [Fig. 1(a)]. In the most stable electronic configuration, described in Fig. 1(a), the unpaired electron lies mostly in a $d_{z 2}$ state, as a consequence of the trigonal distortion along the $c$-axis with a shorter $\mathrm{Cu}-\mathrm{O}$ bond. The spin density on the $\mathrm{Cu}$ atom is 0.74 while 0.15 is on the axial $\mathrm{O}$, according to a Mulliken analysis. The hyperfine coupling constants have been obtained after complete decontraction of the $\mathrm{Cu}$ basis-set to increase the flexibility of the core $s$-functions (see Table II). The isotropic component is in rather good agreement with the experimental value. The negative value of the $a_{\text {iso }}$ indicates that the unpaired spin density is of the minority spin character (beta) since $g_{N}$ for $\mathrm{Cu}$ is positive. This can be explained by an exchange interaction of the spin density more distant from the nucleus, leaving the minority spin density in the region near the nucleus. The dipolar tensor $B$ is axial, as experimentally observed. The quantitative agreement is in this case less satisfactory. The discrepancy is most probably due to the spin-orbit contribution which has not been included in the present calculations. This is found to be essential for the quantitative reproduction of experimental values in the case of transition metal compounds and in particular for $\mathrm{Cu}^{2+}$ complexes. ${ }^{50,51}$ Although largely underestimated, the computed dipolar components make up the major part of the hyperfine coupling constants, in line with the fact that the unpaired electron lies mostly in a d orbital.

\section{2. $C u_{s} Z n_{i}$}

If the experimental process of copper doping is performed by implantation or through a severe thermal annealing in oxygen poor condition it is conceivable that one $\mathrm{Cu}$ atom results in a $\mathrm{Zn}$ atom lattice position while the $\mathrm{Zn}$ is moved in an interstitial site, with consequent formation of $\mathrm{a} \mathrm{Cu}_{\mathrm{s}}$ and a $\mathrm{Zn}_{\mathrm{i}}$. The copresence of these defects $\left(\mathrm{Cu}_{\mathrm{s}} \mathrm{Zn}_{\mathrm{i}}\right)$ has been investigated in two configurations: the two species are close

TABLE II. Spin Hamiltonian parameters for ${ }^{63} \mathrm{Cu}_{\mathrm{s}}{ }^{2+}$. All values are in MHz.

\begin{tabular}{|c|c|c|c|c|c|c|c|c|}
\hline & $\mathrm{A}_{1}$ & $\mathrm{~A}_{2}$ & $\mathrm{~A}_{3}$ & $\mathrm{a}_{\mathrm{iso}}$ & $\mathrm{B}_{1}$ & $\mathrm{~B}_{2}$ & $\mathrm{~B}_{3}$ & Spin \\
\hline Exp. $[13]^{\mathrm{a}}$ & \pm 584.60 & $\mp 692.52$ & $\mp 692.52$ & $\mp 266.81$ & \pm 851.41 & $\mp 425.71$ & $\mp 425.71$ & $\ldots$ \\
\hline Exp. [14] & \pm 593.59 & $\mp 683.53$ & $\mp 683.53$ & $\mp 257.82$ & \pm 851.41 & $\mp 425.71$ & $\mp 425.71$ & $\ldots$ \\
\hline This work $^{\mathrm{b}}$ & +449.60 & -359.17 & -359.17 & -89.58 & +539.18 & -269.59 & -269.59 & 0.74 \\
\hline This work ${ }^{\mathrm{c}}$ & +333.15 & -485.92 & -485.92 & -212.90 & +546.05 & -273.02 & -273.02 & 0.74 \\
\hline
\end{tabular}

${ }^{a}$ We propose a different decomposition of the $A$ tensor into the $a_{\text {iso }}$ and $B$ components than what reported in the experimental Ref. 13 in agreement with the interpretation of Bates (Ref. 45) and Zheng et al. (Ref. 46).

${ }^{\mathrm{b}} \mathrm{Cu}$ basis set from Ref. 32 .

${ }^{\mathrm{c}}$ Fully decontracted $\mathrm{Cu}$ basis set from Ref. 32 . 
(2.4 $\AA$ ) or far apart $(10.0 \AA)$, respectively. When $\mathrm{Cu}_{\mathrm{s}}$ and $\mathrm{Zn}_{\mathrm{i}}$ are in close contact there is a significant lattice rearrangement resulting in the $\mathrm{Cu}$ and $\mathrm{Zn}$ atoms actually sharing the same lattice site in a so called split-interstitial configuration [see Fig. 1(b)]. On the contrary, when the defects are well separated they are almost unperturbed. In both cases, only one electron has been transferred from the $\mathrm{Zn}$ impurity to the $\mathrm{Cu}_{\mathrm{s}}$ while a second electron lies in a perturbed host state [see lower panel in Fig. 1(b)]. These are shallow donor species with thermodynamic transition levels $\varepsilon^{\text {therm }}(+1 / 0)$ computed to be 0.11 and $0.15 \mathrm{eV}$ from the $\mathrm{CB}$ minimum, respectively (see Table I). However, it is relevant to stress that the second configuration is $1.5 \mathrm{eV}$ less stable than the first one.

\section{B. Interstitial copper: $\mathrm{Cu}_{\mathrm{i}}$}

A recent combined experimental and theoretical study has shown that particular conditions of $\mathrm{Cu}$ doping may result in formation of interstitial $\mathrm{Cu}^{20}$ Both tetrahedral and octahedral interstitial voids exist in bulk $\mathrm{ZnO}$. Interstitial $\mathrm{Zn}$ species were computed to be $0.9 \mathrm{eV}$ more stable in the larger octahedral cavity, ${ }^{52}$ thus we assume that the same interstice is also favored for $\mathrm{Cu}_{\mathrm{i}}$ species [see Fig. 2(a)]. Similar structural relaxations are observed for $\mathrm{Cu}_{\mathrm{i}}$ and $\mathrm{Zn}_{\mathrm{i}}$, with almost identical TM-O (2.07 $\AA$ ) and TM-Zn distances (2.44-2.59 ̊ versus $2.42-2.50 \AA$, respectively). In contrast to $\mathrm{Zn}_{\mathrm{i}}$, which is a double electron shallow donor, ${ }^{21} \mathrm{Cu}_{\mathrm{i}}$ is expected to be a single shallow donor, which is confirmed by the present calculations [see lower scheme of Fig. 2(a)]. It is noteworthy that, unlike $3 d$ states of $\mathrm{Zn}_{\mathrm{i}}$ which are deep inside the $\mathrm{VB}$, the $3 d$ states of $\mathrm{Cu}_{\mathrm{i}}$ lie inside the band gap $(0.3 \mathrm{eV}$ above the VB top), in line with a larger stabilization energy of $3 d$ orbitals with increasing atomic number. The resulting donor state is a largely delocalized perturbed host state, just below the bottom of $\mathrm{ZnO}$ conduction band. The thermodynamic transition level $\varepsilon^{\text {therm }}(+1 / 0)$ for $\mathrm{Cu}_{\mathrm{i}}$ defect center is computed to be $0.13 \mathrm{eV}$ from the CB minimum (see Table I). This computed value can be directly compared with the donor ionization energy of $0.088 \mathrm{eV},{ }^{20}$ experimentally derived from a high resolution electron energy loss (HREEL) study. The agreement is extraordinary good, as discussed in a previous work. ${ }^{20}$

\section{Magnetic properties: $\mathrm{Cu}_{\mathrm{s}} \mathrm{Cu}_{\mathrm{s}}$}

The magnetic properties resulting from $\mathrm{Cu}$-doping of $\mathrm{ZnO}$ have been intensively investigated ${ }^{22-27}$ with the final goal of achieving a suitable ferromagnetic material for spintronic applications. The experimental evidences are controversial and ferromagnetism has been so far reported for both conductive $p$-type $e^{8,9}$ or $n$-type $e^{53}$ and insulating ${ }^{54,55}$ samples. An accurate description of the direct exchange coupling of $\mathrm{Cu}$ ions is important to clarify $\mathrm{Cu}$-doped $\mathrm{ZnO}$ magnetic properties, and eventually to predict potentially interesting combinations with codopant elements for RTferromagnetism. Hybrid exchange-correlation functionals are precious tools since local spin density approximation (LSDA) and GGA approaches often fail to describe, even qualitatively, strongly localized unpaired charge carriers, due to the spurious delocalization deriving from the incorrect description of the self-interaction. ${ }^{10,56,57}$ This problem can be overcome by adding a percentage of exact Hartree-Fock exchange, as in hybrid functionals, or using an on-site potential and requiring the linear dependence of total energy on the electron occupation, also known as generalized Koopmans' condition. ${ }^{41}$ In this work we use the hybrid B3LYP functional, as implemented in the CRYSTAL06 code, that has been successfully used to describe the magnetic properties of a wide variety of solids. ${ }^{56,58-60}$

We have considered only the first and third nextneighbors $\mathrm{Cu}_{\mathrm{s}}$ since the magnetic interactions are reported to decrease as $r^{-t}$, with $r$ the distance between the $\mathrm{Cu}$ ions and $t$ varying between 11 and $15 .^{61}$ Two configurations are examined, with the $\mathrm{Cu}$ ions lying in the $x y$-plane (perpendicular to the $c$-axis) or along the $z$-axis (equivalent to the $c$-axis, see Fig. 3) and with $\mathrm{Cu}-\mathrm{Cu}$ distance of $3.34 \AA$ (nextneighbors) and $5.27 \AA$ (the third next-neighbors), respectively. The atomic positions are fully relaxed for each configuration and then they are kept fixed for the calculation of FM and AFM states. The energy differences, $\Delta E=E^{\mathrm{AFM}}-E^{\mathrm{FM}}$, accounting only for the different magnetic interactions, are negligible, $+3 \mathrm{meV}$ and $+1 \mathrm{meV}$ for $x y$-plane and $z$-axis configurations, respectively. The unpaired electrons in both structural configurations and in both magnetic states are largely localized in a $d$ state of the $\mathrm{Cu}$ ions with a small delocalization on one next-neighboring $\mathrm{O}$ ion (see Fig. 3). In the lower panels of Fig. 3 a schematic representation of the electronic structure is reported showing that the $\mathrm{Cu}$ d states in the FM state of both structural configurations are localized in the proximity of the VB top with the two unoccupied beta spin components (one for each $\mathrm{Cu}_{\mathrm{s}}$ ) lying high in the band gap of $\mathrm{ZnO}$. The atomic spin density from the Mulliken analysis on the two $\mathrm{Cu}$ species is $0.74 \mathrm{e}$, indicating a high spin localization. Comparison of total energies of $z$-axis and $x y$-plane configurations in the FM magnetic states (FM) shows that the most stable species is the $z$-axis one by $8 \mathrm{meV}$.

In Table III total energy differences from previous works for comparison with the present hybrid functional results are reported. It is evident that for the $z$-axis configuration, where the two $\mathrm{Cu}$ ions are further apart, the FM and AFM solutions are basically degenerate or very close in energy for all methods. For the $x y$-plane configuration with two next neighboring $\mathrm{Cu}$ ions, apart from a small supercell B3LYP calculation which is totally off with respect to the other values, it is possible to observe that LDA and GGA functionals overestimate the relative stability of the FM solution, while $\mathrm{LDA}+\mathrm{U},{ }^{62} \mathrm{GGA}+\mathrm{U}^{24}$ and present $\mathrm{B} 3 \mathrm{LYP}$ calculations are in closer agreement with a tiny or negligible energy difference. Note that the supercell models used for these three calculations are rather different which may account for the slight differences in energy (LDA+U:32 versus GGA+U:72 versus B3LYP:192 atoms). These short overview of the data is fully consistent with the LDA and GGA poor performances when describing localized unpaired electrons as discussed above. The larger and spurious delocalization intrinsic of local spin density approximation (LSDA) and 


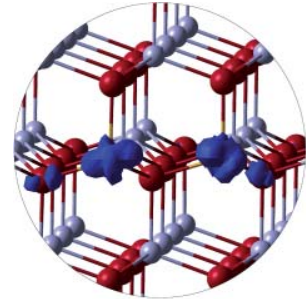

$\alpha$
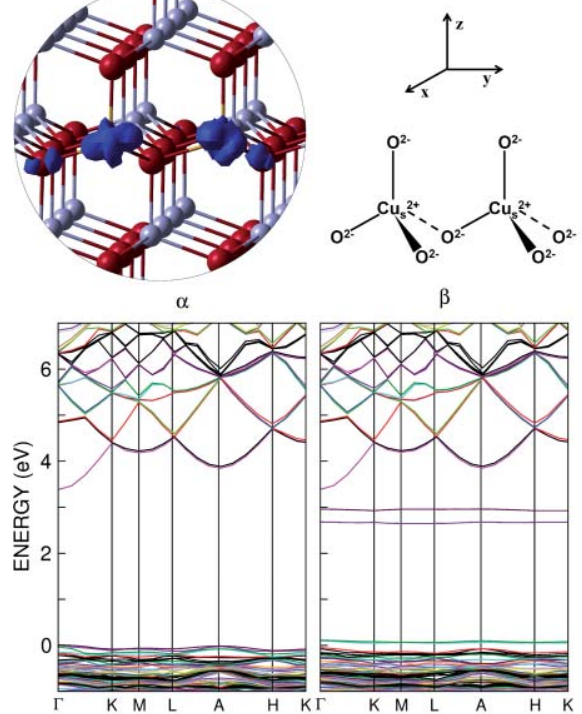

$\beta$
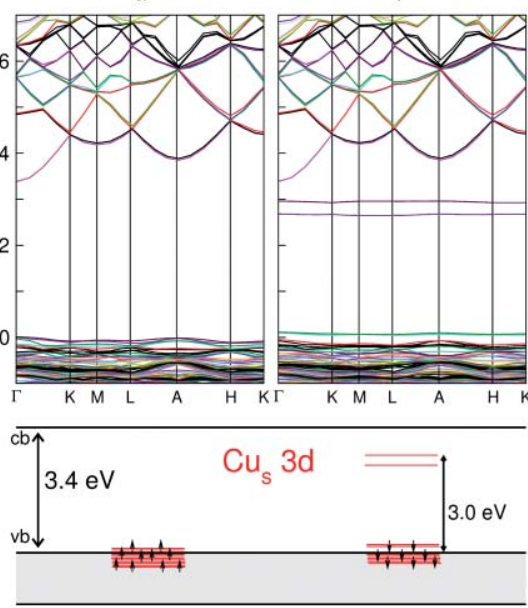

a) xy-plane

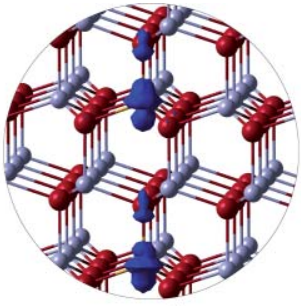

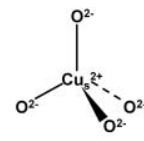<smiles>O=[PH](=O)(O)OCCO</smiles>

$\beta$

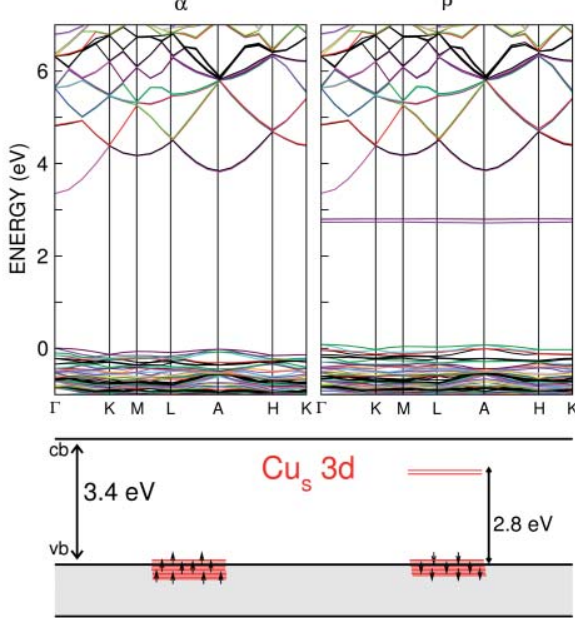

b) z-axis

FIG. 3. Upper panel: spin density plots and schematic structures of the $\mathrm{Cu}_{\mathrm{s}} \mathrm{Cu}_{\mathrm{s}}$ species in bulk $\mathrm{ZnO}$ for the FM states in the (a) $x y$-plane configuration and (b) $\mathrm{z}$-axis configuration. $\mathrm{Zn}, \mathrm{O}$, and $\mathrm{Cu}$ are represented by gray, red, and yellow spheres, respectively. Lower panel: band structures for the two models in the FM state together with a schematic representation of the electronic structure (from Kohn-Sham eigenvalues in $\Gamma$ ).

GGA methods is the probable reason for the overestimated magnetic interaction between the two $\mathrm{Cu}$ centers occupying the next-neighboring sites (FM versus AFM for $x y$-plane, see Table III).

Concluding, the B3LYP results from this work indicate that $\mathrm{Cu}_{\mathrm{s}}$ impurities in $\mathrm{ZnO}$ do not present any direct magnetic interaction and would be magnetically disordered at room temperature. The observed RT-ferromagnetism ${ }^{8,9,53-55}$ of $\mathrm{Cu}$-doped $\mathrm{ZnO}$ might be induced by $\mathrm{Cu}_{\mathrm{s}}$ interaction with other magnetically active impurities. ${ }^{63,64}$ However, this analysis goes beyond the purpose of the present study and will be the object of future work.

TABLE III. Total energy difference $\Delta E=E^{\mathrm{AFM}}-E^{\mathrm{FM}}$ (in meV) for $x y$ plane (next-neighbors) and $z$-axis (the third next-neighbors) configurations with different functional and supercell-size models, as reported in literature.

\begin{tabular}{lcccc}
\hline \hline & & & \multicolumn{2}{c}{$\Delta \mathrm{E}$} \\
\cline { 3 - 5 } & DFT method & $\mathrm{N}^{\circ}$ atoms & $x y$-plane & $z$-axis \\
\hline This work & B3LYP & 192 & +3 & +1 \\
Ref. 62 & LDA & 32 & $\sim+90$ & $\sim+10$ \\
Ref. 62 & LDA+U & 32 & $\sim+25$ & $\sim 0$ \\
Ref. 23 & GGA & 72 & $\sim+130$ & $\sim+10$ \\
Ref. 24 & GGA & 32 & +129 & $\ldots$ \\
& & 48 & +120 & $\ldots$ \\
& & 72 & +130 & $\ldots$ \\
Ref. 24 & GGA+U & 72 & +160 & $\ldots$ \\
Ref. 26 & B3LYP & 32 & -669 & +13 \\
\hline \hline
\end{tabular}

\section{Copper clustering: $\mathrm{Cu}_{s} \mathrm{Cu}_{i}, \mathrm{Cu}_{s} 2 \mathrm{Cu}_{\mathrm{i}}$}

\section{1. $\mathrm{Cu}_{s} \mathrm{Cu}$}

Larger concentrations of $\mathrm{Cu}$ species in bulk $\mathrm{ZnO}$ may lead to more complex systems where both substitutional and interstitial copper species are present. These systems may present some interesting or unexpected electronic properties. For example, a substitutional and nearby interstitial copper pair $\left(\mathrm{Cu}_{\mathrm{s}} \mathrm{Cu}_{\mathrm{i}}\right)$, after full structural relaxation, are found to actually share an original $\mathrm{Zn}$ lattice position. Thus the two copper species are perfectly equivalent and cannot be distinguished into a substitutional and interstitial copper any more [see Fig. 2(b)]. This final configuration is obtained starting from a copper atom both in a tetrahedral or an octahedral void. Both species hold $\mathrm{a} \mathrm{Cu}^{+}$formal oxidation state since the original shallow donor $\mathrm{Cu}_{\mathrm{i}}$ species donates the high lying electron to the original deep acceptor $\mathrm{Cu}_{\mathrm{s}}$ species. This results in a close shell configuration as represented schematically in the lower panel of Fig. 2(b). The nearby $\mathrm{Cu}_{\mathrm{s}} \mathrm{Cu}_{\mathrm{i}}$ pair is largely favored $(1.1 \mathrm{eV})$ with respect to the noninteracting $\mathrm{Cu}_{\mathrm{s}}$ and $\mathrm{Cu}_{\mathrm{i}}$ species, far apart in the supercell model, even though the compensating electron transfer is analogously observed.

\section{2. $\mathrm{Cu}_{s} 2 \mathrm{Cu}_{i}$}

A second interstitial copper species in the presence of a $\mathrm{Cu}_{\mathrm{s}} \mathrm{Cu}_{\mathrm{i}}$ pair $\left[\mathrm{Cu}_{\mathrm{s}} 2 \mathrm{Cu}_{\mathrm{i}}\right.$, see Fig. 2(c)] reestablishes a donor character of the overall system $\left(\varepsilon^{\text {therm }}(+1 / 0)=0.08 \mathrm{eV}\right.$ from CB minimum), with a single unpaired electron in a perturbed 

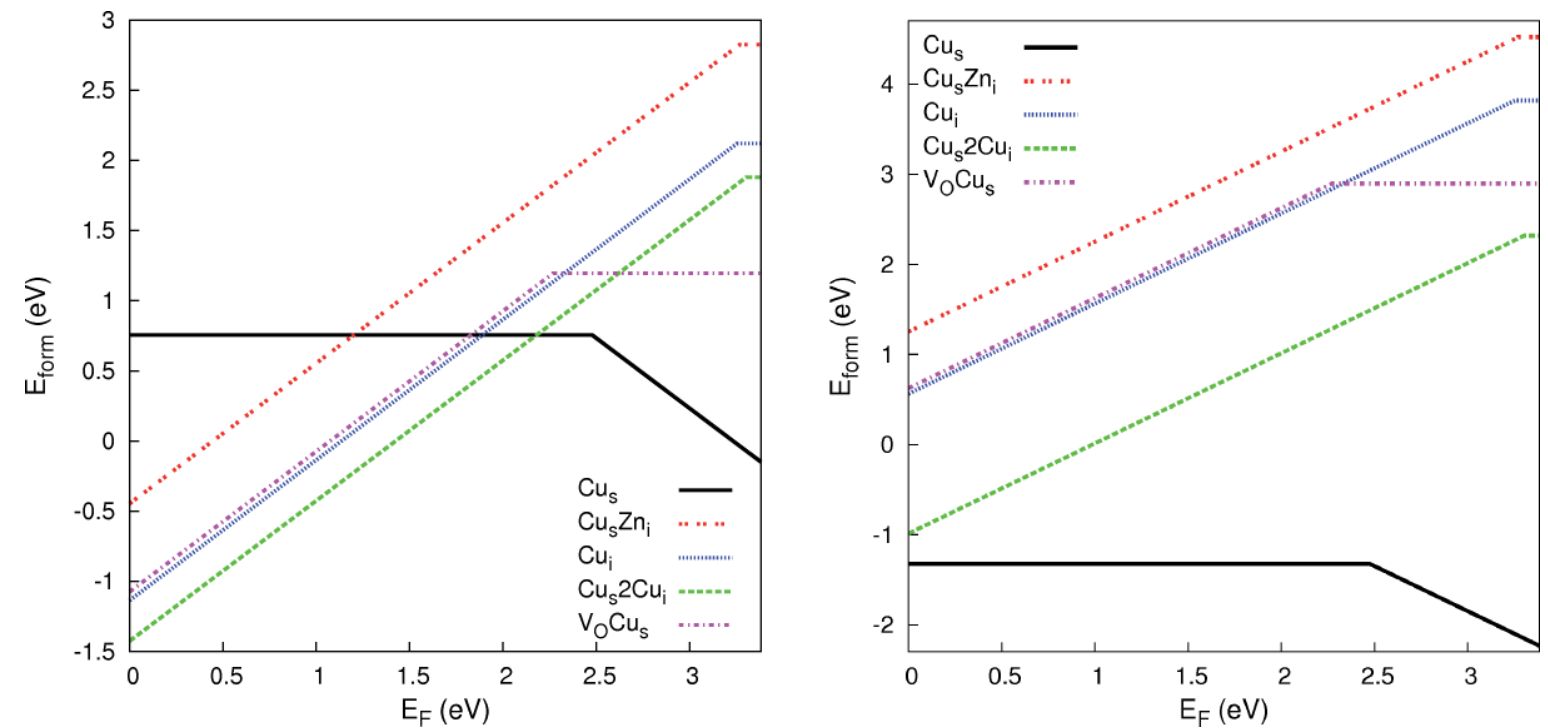

FIG. 4. Formation energy of Cu defects as a function of the Fermi level (left panel) at the oxygen poor limit $\left(\Delta \mu^{\prime} \mathrm{O}=-3.78, \Delta \mu^{\prime} \mathrm{Zn}=0, \Delta \mu^{\prime} \mathrm{Cu}=0\right)$ and (right panel) at the oxygen rich limit $\left(\Delta \mu^{\prime} \mathrm{O}=0, \Delta \mu^{\prime} \mathrm{Zn}=-3.78, \Delta \mu^{\prime} \mathrm{Cu}=-1.70\right)$. The slope corresponds to the charge state of the defect considered.

host state [see the schematic representation of the electronic structure in Fig. 2(c)]. The second $\mathrm{Cu}_{\mathrm{i}}$ is almost unperturbed in the original interstitial position both if close to or far apart from the $\mathrm{Cu}_{\mathrm{s}} \mathrm{Cu}_{\mathrm{i}}$ fragment. The former configuration is favored by $0.5 \mathrm{eV}$ indicating a tendency of $\mathrm{Cu}$ species to cluster, as we will discuss below (see Sec. III F).

\section{E. Interaction with oxygen vacancies: $\mathrm{Cu}_{\mathrm{s}} \mathrm{V}_{\mathrm{O}}$}

Some recent theoretical works ${ }^{24,25,62,65}$ analyzed the potential interaction between transition metal dopants and oxygen vacancies, $\mathrm{V}_{\mathrm{O}}$, in $\mathrm{ZnO}$. Oxygen-poor conditions favor oxygen vacancies formation which are double donor defects. ${ }^{21,66}$ We have investigated the interplay of a single neutral $\mathrm{V}_{\mathrm{O}}$ with a nearby (in both axial and equatorial positions) or a distant substitutional copper species $\left(\mathrm{Cu}_{\mathrm{s}}\right)$. The situation with copper substituting one of the nearest zinc atoms around the vacancy is about $0.4 \mathrm{eV}$ more stable [Fig. 1(c)].

Partial charge transfer from the vacancy to the metal is observed when the two impurities are in direct contact, with the unpaired electron still partially localized in a $\mathrm{Cu} 3 d_{z 2}$ state (0.3e from the Mulliken spin population analysis), as shown by the spin density plot in Fig. 1(c). The partial spin localization on $\mathrm{Cu}$ is true for the vacancy in both axial (reported in the figure) and equatorial positions with respect to the $\mathrm{Cu}$ ion. The $\mathrm{V}_{\mathrm{O}}$ state is commonly a doubly occupied state, ${ }^{67}$ however, in the presence of an axial neighboring $\mathrm{Cu}$ ion, it is mixed with the $\mathrm{Cu} d_{z 2}$ state, as proved by the projected density of states (see Fig. S3 in Ref. 34) and, most importantly, it becomes singly occupied [see the schematic representation of the electronic structure in the bottom panel of Fig. 1(c)]. This system $\left(\mathrm{Cu}_{\mathrm{s}} \mathrm{V}_{\mathrm{O}}\right)$, with an unpaired electron in $\mathrm{V}_{\mathrm{O}}$, is still a rather deep donor with $\varepsilon^{\text {therm }}(+1 / 0)=2.27 \mathrm{eV}$ from VB (see Table I). We wish to note that these calculations could not be performed in the presence of ghost functions on the vacancy site because of technical problems related to the vicinity of the $\mathrm{Cu}$ ion.
The absence of ghost functions may induce an enhanced and spurious mixing of the $\mathrm{V}_{\mathrm{O}}$ state with the $\mathrm{Cu} d$ states.

When the two impurities are far apart in the supercell model (about $10 \AA$ ) there is no electron transfer from the vacancy to the copper ion $(0.74 \mathrm{e}$ on $\mathrm{Cu}$ from Mulliken spin population analysis).

\section{F. Relative stability of Cu species}

Finally, the energetics for the various copper defects which have been investigated in this study and presented in the previous sections is compared. The relative stability is discussed in terms of formation energy $\left(E_{\text {form }}=\right.$ energy cost to form the defect species) and analyzed as a function of (a) the Fermi level of the system (Fig. 4) and (b) the oxygen chemical potential (Fig. 5). The oxygen chemical potential, $\mu_{\mathrm{O}}$, is a parameter which characterizes the oxygen environment during synthesis. The environment acts as a reservoir, which can give or take any amount of oxygen without changing its temperature and pressure. Low values of $\mu_{\mathrm{O}}$ correspond to oxygen poor conditions and conversely, high values of $\mu_{\mathrm{O}}$ correspond to oxygen rich conditions. We take $\mu_{\mathrm{O}}=1 / 2 \mu\left(\mathrm{O}_{2}\right)+\Delta \mu_{\mathrm{O}}^{\prime}$ with $\Delta \mu_{\mathrm{O}}^{\prime}$ ranging from -3.78 to $0 \mathrm{eV}$ where the value of $\Delta \mu^{\prime}{ }_{\mathrm{O}}=0$ corresponds to the oxygen rich limit at which oxygen condensation will occur, whereas $\Delta \mu^{\prime}{ }_{\mathrm{O}}=-3.78$ is the calculated formation energy of wurtzite $\mathrm{ZnO}$ (to be compared with the experimental heat of formation of $-3.63 \mathrm{eV}) .{ }^{68}$

(a) We first focus the attention on the dependence of the relative stability of the various defect species with the Fermi level of the system and fix the oxygen chemical potential at the oxygen poor $\left[\mu_{\mathrm{O}}=1 / 2 \mu\left(\mathrm{O}_{2}\right)-3.78 \mathrm{eV}\right.$, Fig. 4 left panel] and at the oxygen rich $\left[\mu_{\mathrm{O}}=1 / 2 \mu\left(\mathrm{O}_{2}\right)\right.$, Fig. 4 right panel] limits.

$$
E_{\text {form }-D, q}\left(E_{F}\right)=E_{D, q}-E_{H}+\sum n_{i} \mu_{i}+q\left[E_{v}+E_{F}\right],
$$




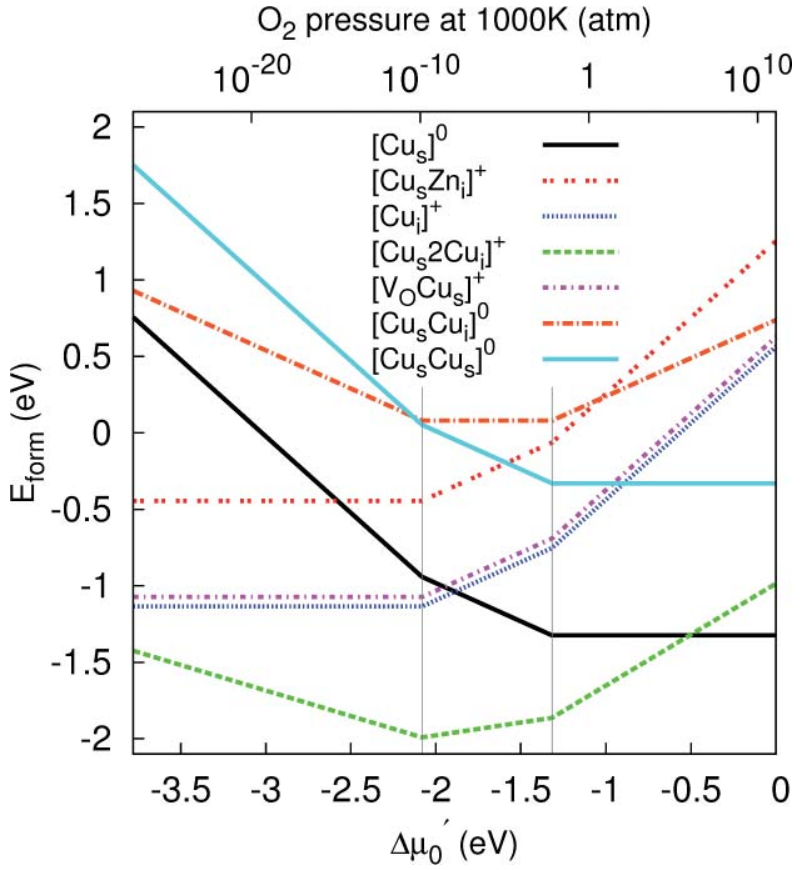

FIG. 5. Formation energy of $\mathrm{Cu}$ defects as a function of delta oxygen chemical potential $\Delta \mu^{\prime} O$ at the zero Fermi level $\left(E_{F}=0\right)$. Note that there are three regions in function of the predominant equilibrium, i.e., $\mathrm{Cu}$ metal, $\mathrm{Cu}_{2} \mathrm{O}$, and $\mathrm{CuO}$, see text for details.

where $D$ is the defect; $q$ is the dimensionless charge state of the defect (e.g., $+1,0,-1) ; E_{D, q}$ and $E_{H}$ are the total energies of the host+defect and the host-only supercells, respectively; $E_{v}$ is the bulk valence band maximum; $E_{F}$ is the Fermi level referenced to the bulk valence band maximum; $n_{i}$ is the number of added or removed atoms (negative and positive values, respectively) to create the defect; and $\mu_{i}$ is the chemical potential of the defect species. The range of Fermi level considered goes from the top of the valence band to the bottom of the conduction band. Only the portion of the curves relative to the most stable charge state at a certain Fermi level is reported. The slope of the curve identifies the charge state: positive slope corresponds to $q=+1$, no slope corresponds to $q=0$, negative slope corresponds to $q=-1$.

At oxygen poor conditions (Fig. 4 left panel), $\mathrm{Cu}_{\mathrm{s}} \mathrm{Zn}_{\mathrm{i}}$ is $0.7 \mathrm{eV}$ less stable than $\mathrm{Cu}_{\mathrm{i}}$. The shallow donor $\mathrm{Cu}_{\mathrm{i}}$ is predominant for a wide range of Fermi level values, confirming the facility to obtain $n$-type conductivity in $\mathrm{ZnO}$. Interstitial copper species are even more stable by few tenths of an $\mathrm{eV}$ when a donor-acceptor copper pair $\left(\mathrm{Cu}_{\mathrm{s}} 2 \mathrm{Cu}_{\mathrm{i}}\right)$ is present in the neighborhood, indicating a tendency of copper defects to cluster in bulk $\mathrm{ZnO}$. Cu-doping is therefore experimentally expected to produce inhomogeneously doped regions as reported by Sudakar et al. ${ }^{69}$ and calculated by Huang et al. ${ }^{23}$ Going toward higher Fermi levels $\left(E_{F}>2.18 \mathrm{eV}\right)$, i.e., for electron rich systems, the $\mathrm{Cu}_{\mathrm{s}}$ becomes thermodynamically the most stable species. At oxygen rich conditions, the situation changes drastically with $\mathrm{Cu}_{\mathrm{s}}$ becoming the most stable copper defect at any Fermi level (Fig. 4 right panel).

(b) The dependence of the formation energy for the most stable charge states at the zero Fermi level $\left(E_{F}=0\right)$ of all the $\mathrm{Cu}$-doped models considered in this work is now analyzed. In Fig. 5, we report the formation energies as a function of $\Delta \mu^{\prime}$ o, according to the formula

$$
\begin{aligned}
& E_{\text {form }-D}\left(\Delta \mu_{\mathrm{O}}^{\prime}\right)=1 / n_{\mathrm{Cu}} E_{D}-1 / n_{\mathrm{Cu}} E_{H}+1 / n_{\mathrm{Cu}} \\
& \times\left[-n_{\mathrm{Cu}} \mu_{\mathrm{Cu}}+n_{\mathrm{Zn}} \mu_{\mathrm{Zn}}+n_{\mathrm{O}}\left(1 / 2 \mu\left(\mathrm{O}_{2}\right)+\Delta \mu_{\mathrm{O}}^{\prime}\right)\right],
\end{aligned}
$$

where $n_{\mathrm{Cu}}$ is the number of $\mathrm{Cu}$ atoms, $n_{\mathrm{Zn}}$ is the number of removed $\mathrm{Zn}$ atoms and $n_{\mathrm{O}}$ is the number of removed oxygen atoms per supercell in the model considered. For copper and zinc we use the chemical potential of bulk metals. However, this approximation is correct at oxygen poor conditions. With increasing oxygen concentration or for less negative $\Delta \mu_{\mathrm{O}}^{\prime}$, the copper oxides $\left(\mathrm{Cu}_{2} \mathrm{O}\right.$ and $\left.\mathrm{CuO}\right)$ and zinc oxide $(\mathrm{ZnO})$ formation become feasible. Therefore, we consider the following system of equations:

$$
\left\{\begin{array}{c}
\Delta \mu_{\mathrm{Cu}}^{\prime} \leq 0, \\
2 \Delta \mu_{\mathrm{Cu}}^{\prime}+\Delta \mu_{\mathrm{O}}^{\prime} \leq E_{\mathrm{form}}^{\mathrm{Cu} \mathrm{O}}(\text { calculation }-2.08, \text { experimental }-1.75), \\
\Delta \mu_{\mathrm{Cu}}^{\prime}+\Delta \mu_{\mathrm{O}}^{\prime} \leq E_{\mathrm{form}}^{\mathrm{CuO}}(\text { calculation }-1.70, \text { experimental }-1.64),
\end{array}\right.
$$

where the formation energies $E_{\text {form }}^{\mathrm{Cu}_{2} \mathrm{O}}$ and $E_{\text {form }}^{\mathrm{CuO}}$ of the oxides have been computed with the same computational setup as for all the other calculations and are in good agreement with the experimental heats of formation..$^{70}$ Solving the system of equations above, we obtained the following values for $\Delta \mu_{C u}^{\prime}$ in different ranges of $\Delta \mu_{\mathrm{O}}^{\prime}$ :

$$
\begin{gathered}
\Delta \mu_{C u}^{\prime}=0 \text { in the range }-3.78 \leq \Delta \mu_{O}^{\prime} \leq-2.08 \\
\Delta \mu_{C u}^{\prime}=\left(-2.08-\Delta \mu_{O}^{\prime}\right) / 2 \text { in the range } \\
-2.08 \leq \Delta \mu_{O}^{\prime} \leq-1.32
\end{gathered}
$$

$\Delta \mu_{C u}^{\prime}=\left(-1.70-\Delta \mu_{O}^{\prime}\right)$ in the range $-1.32 \leq \Delta \mu_{O}^{\prime} \leq 0$

and $\Delta \mu_{Z n}^{\prime}=\left(-3.78-\Delta \mu_{O}^{\prime}\right)$ for all the range of $\Delta \mu_{O}^{\prime}$.

From the graph in Fig. 5, we observe that the clustering of copper species is energetically favored for a large range of oxygen chemical potential, especially at oxygen poor conditions. Interstitial copper is also preferred at oxygen poor conditions although it may compete with substitutional copper in the presence of oxygen vacancies. This was not obvious and 
has the meaning that forcing an interstitial additional copper atom in the lattice costs approximately as substituting a zinc atom and removing an oxygen atom altogether. We also learn that interstitial copper $\left(\mathrm{Cu}_{\mathrm{i}}\right)$ is thermodynamically preferred to interstitial zinc $\left(\mathrm{Cu}_{\mathrm{s}} \mathrm{Zn}_{\mathrm{i}}\right)$, i.e., a copper atom cannot push a zinc atom from its lattice position into an interstitial site. Finally, the substitutional copper species becomes favored at oxygen rich conditions, as expected.

\section{CONCLUSIONS}

The purpose of this work is to provide an overview on copper doped bulk $\mathrm{ZnO}$ based on hybrid exchange-correlation functional calculations. This approach is nowadays the best compromise between accuracy and computational cost for describing semiconductor defect properties. B3LYP computed band gap is in excellent agreement with the experimental one, which gives the proper ground for comparing calculated transition energy levels with defect states position in the band gap as obtained from spectroscopic data. This popular hybrid functional also provides a better description of spin localization and spin properties for unpaired electron systems with respect to standard LSDA and GGA methods.

Copper has been investigated in a variety of sites and concentrations, also in the presence of intrinsic defects such as oxygen vacancies. Computed properties have been compared to experimental data. Substitutional copper is confirmed to be a deep acceptor species while interstitial copper is found to be a shallow donor one with transition energy levels in very good agreement with the position of $\mathrm{Cu}$ defects states from spectroscopic data. Hyperfine coupling constants with ${ }^{63} \mathrm{Cu}$ nucleus for $\mathrm{Cu}_{\mathrm{s}}$ are computed for the first time and prove a negative Fermi contact term of the isotropic component and large values for the dipolar component. Ferromagnetic and antiferromagnetic spin configurations have been compared in different structural configurations for substitutional (to $\mathrm{Zn}$ ) copper species and with previously reported data in literature. Although the ferromagnetic is found to be the true ground state within our computational setup, the energy difference with respect to the antiferromagnetic state is so tiny that magnetic order for this type of system can be excluded. The presence of a higher concentration of copper impurities is found to favor copper clustering. Intrinsic defects such as oxygen vacancies may spontaneously transfer one electron to substitutional copper species. The thermodynamic analysis of the relative stability of the various copper impurities considered in this work indicates that interstitial copper is favored for a large range of oxygen chemical potentials. Substitutional copper is preferred at oxygen rich conditions. For higher concentration of copper in $\mathrm{ZnO}$ copper clustering is preferred and reduces the cost of doping.

\section{ACKNOWLEDGMENTS}

We wish to thank Dr. Yuemin Wang, Dr. Hengshan Qiu, and Prof. G. Pacchioni for useful discussions. F. G. thanks the PCAM Research Training program supporting his stay in Bochum. Regione Lombardia and CILEA Consortium, through a LISA Initiative (Laboratory for Interdisciplinary Advanced Simulation), are gratefully acknowledged.

${ }^{1}$ Ü. Özgür, Ya. I. Alivov, C. Liu, A. Teke, M. A. Reshchikov, S. Doğan, V. Avrutin, S.-J. Cho, and H. Morkoç, J. Appl. Phys. 98, 041301 (2005).

${ }^{2}$ C. Klingshirn, J. Fallert, H. Zhou, J. Sartor, C. Thiele, F. Maier-Flaig, D. Schneider, and H. Kalt, Phys. Status Solidi B 247, 1424 (2010).

${ }^{3}$ S. B. Ogale, Adv. Mater. 22, 3125 (2010).

${ }^{4}$ S. J. Pearton, W. H. Heo, M. Ivill, D. P. Norton, and T. Steiner, Semicond. Sci. Technol. 19, R59 (2004).

${ }^{5}$ T. Dietl, H. Ohno, F. Matsukura, J. Cibert, and D. Ferrand, Science 287, 1019 (2000).

${ }^{6}$ T. Dietl, Semicond. Sci. Technol. 17, 377 (2002).

${ }^{7}$ K.-S- Ahn, T. Deutsch, Y. Yan, C.-S. Jiang, C. L. Perkins, J. Turner, and M. Al-Jassim, J. Appl. Phys. 102, 023517 (2007).

${ }^{8}$ D. J. Keavney, D. B Buchholz, Q. Ma, and R. P. H. Chang, Appl. Phys. Lett. 91, 012501 (2007).

${ }^{9}$ D. B. Buchholz, R. P. H. Chang, J. H. Song, and J. B. Ketterson, Appl. Phys. Lett. 87, 082504 (2005).

${ }^{10}$ A. Zunger, S. Lany, and H. Raebiger, Phys. 3, 53 (2010).

${ }^{11}$ R. Dingle, Phys. Rev. Lett. 23, 579 (1969).

${ }^{12}$ A. Cetin, R. Kibar, M. Ayvacikli, N. Can, Ch. Buchal, P. D. Townsend, A. L. Stepanov, T. Karali, and S. Selvi, Nucl. Instrum. Methods Phys. Res. B 249, 474 (2006).

${ }^{13}$ R. E. Dietz, H. Kamimura, M. D. Sturge, and A. Yariv, Phys. Rev. 132, 1559 (1963).

${ }^{14}$ I. Broser and M. Schulz, Solid State Commun. 7, 651 (1969).

${ }^{15}$ A. D. Becke, J. Chem. Phys. 98, 5648 (1993).

${ }^{16}$ C. Lee, W. Yang, and R. G. Parr, Phys. Rev. B 37, 785 (1988).

${ }^{17}$ R. Dovesi, V. R. Saunders, C. Roetti, R. Orlando, C. M. Zicovich-Wilson, F. Pascale, B. Civalleri, K. Doll, N. M. Harrison, I. J. Bush, Ph. D'Arco, and M. Llunell, CRYSTALO6 User's Manual (University of Torino, Torino, 2006).

${ }^{18}$ D. C. Reynolds, D. C. Look, B. Jogai, C. W. Litton, G. Cantwell, and W. C. Harsch, Phys. Rev. B 60, 2340 (1999).

${ }^{19}$ M. D. McCluskey and S. J. Jokela, J. Appl. Phys. 106, 071101 (2009).

${ }^{20}$ H. Qiu, F. Gallino, C. Di Valentin, and Y. Wang, Phys. Rev. Lett. 106, 066401 (2011)

${ }^{21}$ F. Gallino, G. Pacchioni, and C. Di Valentin, J. Chem. Phys. 133, 144512 (2010).

${ }^{22}$ M. Ferhat, A. Zaoui, and R. Ahuja, Appl. Phys. Lett. 94, 142502 (2009).

${ }^{23}$ D. Huang, Y.-J. Zhao, D.-H. Chen, and Y.-Z. Shao, Appl. Phys. Lett. 92, 182509 (2008).

${ }^{24}$ L. M. Huang, A. L. Rosa, and R. Ahuja, Phys. Rev. B 74, 075206 (2006).

${ }^{25}$ L.-H. Ye, A. J. Freeman, and B. Delley, Phys. Rev. B 73, 033203 (2006).

${ }^{26}$ X. Feng, J. Phys. Condens. Mat. 16, 4251 (2004).

${ }^{27}$ M. S. Park and B. I. Min, Phys. Rev. B 68, 224436 (2003).

${ }^{28}$ Y. Noel, C. M. Zicovich-Wilson, B. Civalleri, Ph. D'Arco, and R. Dovesi, Phys. Rev. B 65, 014111 (2001).

${ }^{29}$ J. E. Jaffe and A. C. Hess, Phys. Rev. B 48, 7903 (1993).

${ }^{30}$ M. D. Towler, R. Dovesi, and V. R. Saunders, Phys. Rev. B 52, 10150 (1995).

${ }^{31}$ T. Homann, U. Hotje, M. Binnewies, A. Börger, K. D. Becker, and T. Bredow, Solid State Sci. 8, 44 (2006).

${ }^{32}$ K. Doll and N. M. Harrison, Chem. Phys. Lett. 317, 282 (2000).

${ }^{33}$ J. A. Weil, J. R. Bolton, and J. E. Wertz, Electron Paramagnetic Resonance, (Wiley, New York, 1994).

${ }^{34}$ See supplementary material at http://dx.doi.org/10.1063/1.3575198 for details on the theoretical approach to compute transition energy levels and for the total and projected (on $\mathrm{Cu}$ ion) B3LYP densities of states of the $\mathrm{Cu}_{\mathrm{s}} \mathrm{V}_{\mathrm{O}}$ species.

${ }^{35}$ In the present work we have only changed the notation for the energy of formation $\left(E_{\text {form }}\right)$ with respect to Ref. $21\left(\Delta H_{\mathrm{f}}\right)$.

${ }^{36}$ U. Wahl, E. Rita, J. G. Correia, E. Alves, J. G. Soares, and ISOLDE Collaboration, Phys. Rev. B 69, 012102 (2004).

${ }^{37}$ Y. Kanai, Jpn. J. Appl. Phys. 30, 703 (1991).

${ }^{38}$ G. Müller and R. Helbig, J. Phys. Chem. Solids 32, 1971 (1971).

${ }^{39}$ F. Herklotz, E. V. Lavrov, and J. Weber, Physica B 404, 4807 (2009).

${ }^{40}$ E. Mollwo, G. Müller, and P. Wagner, Solid State Commun. 13, 1283 (1973) 
${ }^{41}$ S. Lany and A. Zunger, Phys. Rev. B 80, 085202 (2009).

${ }^{42} E_{\text {rel }}^{\prime}$ is the relaxation energy for the neutral charge state in the optimal charged state geometry, as defined in Ref. 21.

${ }^{43}$ Y. Yan, M. M. Al-Jassim, and S.-H. Wei, Appl. Phys. Lett. 89, 181912 (2006).

${ }^{44}$ C. A. Bates and P. E. Chandler, J. Phys. C 4, 2713 (1971).

${ }^{45}$ C. A. Bates, Proc. Phys. Soc. 83, 465 (1964).

${ }^{46}$ W. C. Zheng, L. He, and Y. Mei, Philos. Mag. 89, 789 (2009).

${ }^{47}$ S.-Y. Wu, L.-H. Wei, Z.-H. Zhang, X.-F. Wang, and Y.-X. Hu, Spectrochim. Acta Part A 71, 1307 (2008)

${ }^{48}$ A. Hausmann, B. Schallenberger, and R. Roll, Z. Phys. B: Condens. Matter 40, 1 (1980).

${ }^{49}$ O. N. Matamura, J. Phys. Soc. Jpn 14, 108 (1959).

${ }^{50}$ S. Kossmann, B. Kirchner, and F. Neese, Mol. Phys. 105, 2049 (2007).

${ }^{51}$ K. J. De Almeida, Z. Rinkevicius, H. W. Hugosson, A. C. Ferreira, and H. Agren, Chem. Phys. 332, 176 (2007)

${ }^{52}$ A. Janotti and C. G. Van de Walle, Phys. Rev. B 76, 165202 (2007).

${ }^{53}$ D. L. Hou, X. J. Ye, H. J. Meng, H. J. Zhou, X. L. Li, C. M. Zhen, and G. D. Tang, Appl. Phys. Lett. 90, 142502 (2007).

${ }^{54}$ D. Chakraborti, J. Narayan, and J. T. Prater, Appl. Phys. Lett. 90, 062504 (2007).

${ }^{55}$ T. S. Herng, S. P. Lau, S. F. Yu, H. Y. Yang, X. H. Ji, J. S. Chen, N. Yasui, and H. Inaba, J. Appl. Phys. 99, 086101 (2006).

${ }^{56}$ A. Meyer, F. Pascale, C. M. Zicovich-Wilson, and R. Dovesi, Int. J. Quantum Chem. 110, 338 (2010).

${ }^{57}$ A. Markovits, M. K. Skalli, C. Minot, G. Pacchioni, N. Lòpez, and F. Illas, J. Chem. Phys. 115, 8172 (2001).
${ }^{58}$ I. de P. R. Moreira, F. Illas, and R. L. Martin, Phys. Rev. B 65, 155102 (2002).

${ }^{59}$ I. de P. R. Moreira and R. Dovesi, Int. J. Quantum Chem. 99, 805 (2004).

${ }^{60}$ D. Muñoz, N. M. Harrison, and F. Illas, Phys. Rev. B 69, 085115 (2004).

${ }^{61}$ L. J. de Jongh and R. Block, Physica B 69, 568 (1975).

${ }^{62}$ P. Gopal and N. A. Spaldin, Phys. Rev. B 74, 094418 (2006).

${ }^{63}$ T. S. Herng, S. P. Lau, S. F. Yu, J. S. Chen, and K. S. Teng, J. Magn. Magn. Mater. 315, 107 (2007).

${ }^{64}$ T. S. Herng, D.-C. Qi, T. Berlijn, J. B. Yi, K. S. Yang, Y. Dai, Y. P. Feng, I. Santoso, C. Sánchez-Hanke, X. Y. Gau, A. T. S. Wee, W. Ku, J. Ding, and A. Rusydi, Phys. Rev. Lett. 105, 207201 (2010).

${ }^{65}$ C. D. Pemmaraju, R. Hanafin, T. Archer, H. B. Braun, and S. Sanvito, Phys. Rev. B 78, 054428 (2008).

${ }^{66} \mathrm{The}$ energy cost to form oxygen vacancies in $\mathrm{ZnO}$ has been largely debated in the past. We have determined an energy cost of $3.5 \mathrm{eV}$ with respect to $1 / 2 \mathrm{O}_{2}$. For low oxygen chemical potentials the formation energy decreases considerably and in the limit of oxygen poor conditions it becomes even slightly negative, $-0.3 \mathrm{eV}$.

${ }^{67}$ A. Janotti and C. G. Van De Walle, Rep. Prog. Phys. 72, 126501 (2009).

${ }^{68}$ J. D. Cox, D. D. Wagman, and V. A. Medvedev, CODATA Key Values for Thermodynamics (Hemisphere, New York, 1989).

${ }^{69}$ C. Sudakar, J. S. Thakur, G. Lawes, R. Naik, and V. M. Naik, Phys. Rev. B 75, 054423 (2007)

${ }^{70}$ CRC Handbook of Chemistry and Physics, edited by D. R. Lide, 89th Ed. (CRC Press, Boca Raton, FL, 2008-2009) 